\title{
Impact of household transitions on domestic energy consumption and its applicability to urban energy planning
}

\author{
C The Author(s) 2017. Published by Higher Education Press. This is an open access article under the CC BY license (http:// \\ creativecommons.org/licenses/by/4.0)
}

\begin{abstract}
The household sector consumes roughly 30\% of Earth's energy resources and emits approximately $17 \%$ of its carbon dioxide. As such, developing appropriate policies to reduce the $\mathrm{CO}_{2}$ emissions, which are associated with the world's rapidly growing urban population, is a high priority. This, in turn, will enable the creation of cities that respect the natural environment and the well-being of future generations. However, most of the existing expertise focuses on enhancing the thermal quality of buildings through building physics while few studies address the social and behavioral aspects. In fact, focusing on these aspects should be more prominent, as they cause between $4 \%$ and $30 \%$ of variation in domestic energy consumption. Premised on that, the aim of this study was to investigate the effect in the context of the UK of household transitions on household energy consumption patterns. To achieve this, we applied statistical procedures (e.g., logistic regression) to official panel survey data comprising more than 5500 households in the UK tracked annually over the course of 18 years. This helped in predicting future transition patterns for different household types for the next 10 to 15 years. Furthermore, it enabled us to study the relationship between the predicted patterns and the household energy usage for both gas and electricity. The findings indicate that the life cycle transitions of a household significantly influence its domestic energy usage. However, this effect is mostly positive in direction and weak in magnitude. Finally, we present our developed urban energy model "EvoEnergy" to demonstrate the importance of incorporating such a concept in energy forecasting for effective sustainable energy decision-making.
\end{abstract}

Keywords urban energy planning, household transitions,

Received April 26, 2017; accepted May 23, 2017

Benachir MEDJDOUB ( $₫)$, Moulay Larbi CHALAL

The School of Architecture, Design, and The Built Environment, Nottingham Trent University, Nottingham, NG1 4BU, UK

E-mail: Benachir.Medjdoub@ntu.ac.uk smart cities, energy forecasting, household projection, serious gaming

\section{Introduction}

The UK residential sector is responsible for consuming $27 \%$ of the country's energy and emitting around $19 \%$ of its $\mathrm{CO}_{2}$ (DECC, 2015a). Thus, urban planners are required to implement appropriate measures not only to meet the required $\mathrm{CO}_{2}$ emission targets but also to ensure that development of the built environment occurs in a sustainable way (CIA, 2015). This has motivated researchers worldwide to explore various solutions to the complex problem of energy sustainability. As a result, great expertise has been developed. However, a majority of it addresses the enhancement of buildings' thermal quality and HVAC systems, with less focus on the social and behavioral aspects. This is evident in the nature of measures undertaken by the UK government in recent years, which have focused mainly on dwellings' retrofit, such as green deal assessment (DECC, 2015a). However, considering that $70 \%$ of the UK dwelling stock was insulated in 2013, energy planners need to consider new alternatives. One possibility is to tackle the social and behavioral aspects, especially given the fact that they cause between $4 \%$ to $30 \%$ of variation in domestic energy consumption (Brounen et al., 2012; Gill et al., 2010; Mansouri et al., 1996; Sonderegger, 1978; Van Raaij and Verhallen, 1983). It should be noted that the behavioral aspect is beyond the scope of this work. Please refer to the reviews of Frederiks et al. (2015) and Steg and Vlek (2009). This study does not address the behavioral aspect of the users.

In general, studies focusing on the social aspect determine the impact of socioeconomic factors (e.g., income) on energy consumption. In this way, it is possible to implement the right policy based on each scenario and to define the policy effect prior to and after implementation. 
Many scholars have addressed extensively the effect of such factors in the literature (Bartiaux and Gram-Hanssen, 2005; Druckman and Jackson, 2008; Genjo et al., 2005; Guerra Santin et al. 2009; Santamouris et al., 2007; Wiesmann et al., 2011; Zhou and Teng, 2013). For example, Longhi (2014) studied the change in socioeconomic circumstance of UK households and its degree of influence on household domestic energy figures. However, until now, no study has considered the effect of household demographic transitions on household energy usage patterns. In other words, the effect of moving from one family type to another over time (e.g., from single person to couple without children) has not been previously studied, even though household life cycle is considered a pillar concept in marketing in general and market segmentation in particular ( $\mathrm{Du}$ and Kamakura, 2006). Premised on that, our research aims to bridge this gap by examining the impact of UK household transitions on domestic gas and electricity consumption figures and by defining the socioeconomic and demographic factors affecting the occurrence and nature of those transitions. We believe that integrating this new knowledge in urban energy planning not only improves energy forecasting but also helps generate effective policies targeting residents at various stages of their life cycle. This will be demonstrated through "EvoEnergy," one of our potential applications, which are based on the concept of household transitions.

\section{Structure of the article}

Following the logical sequencing of the research project, this paper has been carefully structured around seven sections. In section 3, the methodological choices made in this research will be discussed in detail. Section 4 focuses on describing the occurring transition patterns in the employed British household panel data from the year 1991 to 2008. Section 5 explores the demographic and socioeconomic factors influencing households' evolution in order to predict future transition patterns for the next 10 years. In section 6 , the relationship between the predicted evolution models and households gas and electricity consumption is investigated. Furthermore, the estimated energy figures are mapped onto the predicted transition patterns of single non-elderly households in the next five years. Finally, Section 7 discusses our developed urban energy model "EvoEnergy" and its modus operandi.

\section{Methodology}

In the study, a quantitative research methodology was embraced, for which the main research method was secondary data analysis. More specifically, we used British household panel survey (BHPS) data to address the research problem. This official panel data set includes more than 5500 households interviewed annually from the year 1991 to 2008 on household socioeconomic, demographic, health conditions, expenditure patterns, and social relationships (ISER, 2016). The ability to study complex dynamic relationships was the main reason behind its use in this study.

To attain the main aim of this study, we carefully structured the research design around three stages of implementation. In Stage 1, existing transition patterns of single non-elderly households in the BHPS data set were explored using some descriptive and analytical statistical techniques, such as cross tabulation. Conversely, the second phase consisted of employing random effects or fixed effects logistic regression models to determine significant socioeconomic as well as demographic factors affecting household transitions. However, the Hausman test of specification, whose null hypothesis indicates that a random model is appropriate, was employed to objectively determine the type of model to use (Greene, 2012). Finally, Stage 3 consists of investigating the effect, magnitude, and direction of association between energy and transition variables using point-biserial correlation analysis.

\subsection{Data screening and transformation}

The following data screening procedures were embraced prior to data analysis. First, due to the fact that energy prices variated significantly from 1991 to 2008, we decided to convert energy expenditure to quantities in $\mathrm{KW} \cdot \mathrm{h}$. This was achieved with the help of official inflation index for domestic gas and electricity, retail price index (RPI), more precisely (DECC, 2015b). After that, all income and energy consumption variables such as, rent, household annual income, were normalized using mainly square root transformations except for annual electricity consumption where log 10 was applied. This was followed by checking and deleting outliers in all continuous variable using the labeling method "outlier labelling rule" (Hoaglin et al., 1986). However, all the extreme values removed were predicted with multiple imputations.

\section{Transition patterns of single non-elderly households from 1991 to 2008}

Figure 1 is a multiple line graph that represents the overall change in the number of various household types in the BHPS data set over the period 1991-2008. In general, it is evident that there was a decrease in the number of single non-elderly households during this period. Furthermore, the number of couple with children and elderly households increased. On the other hand, the proportion of other and lone parent households remained fairly stable. These facts suggest the existence of hidden transition patterns in the analyzed data set. Thus, we utilized the stack bar chart (Fig. 2) to help closely investigate the 


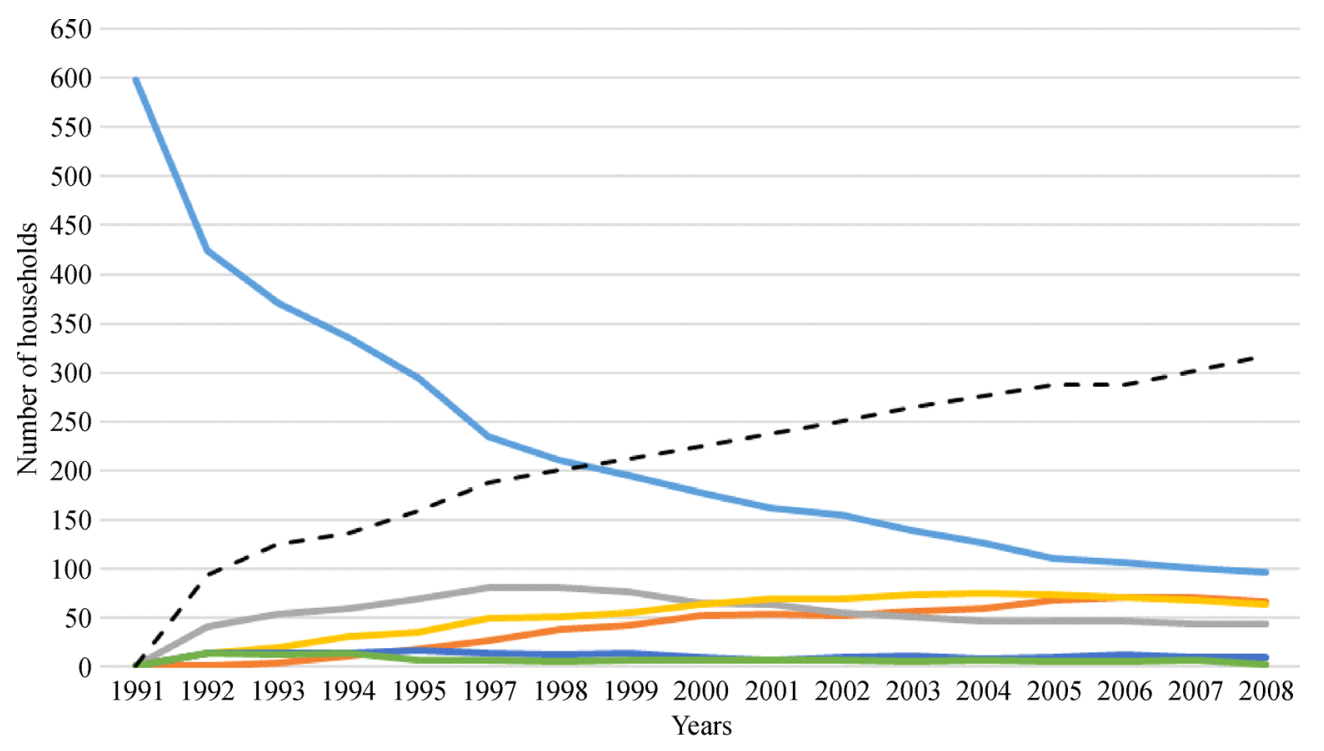

Household type

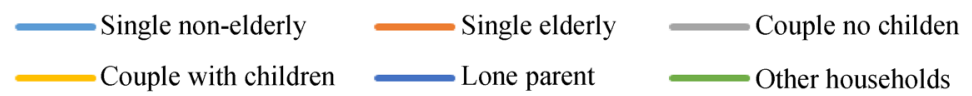

- - - Missing

Fig. 1 Change in the number of different households in the BHPS data set between 1991 and 2008

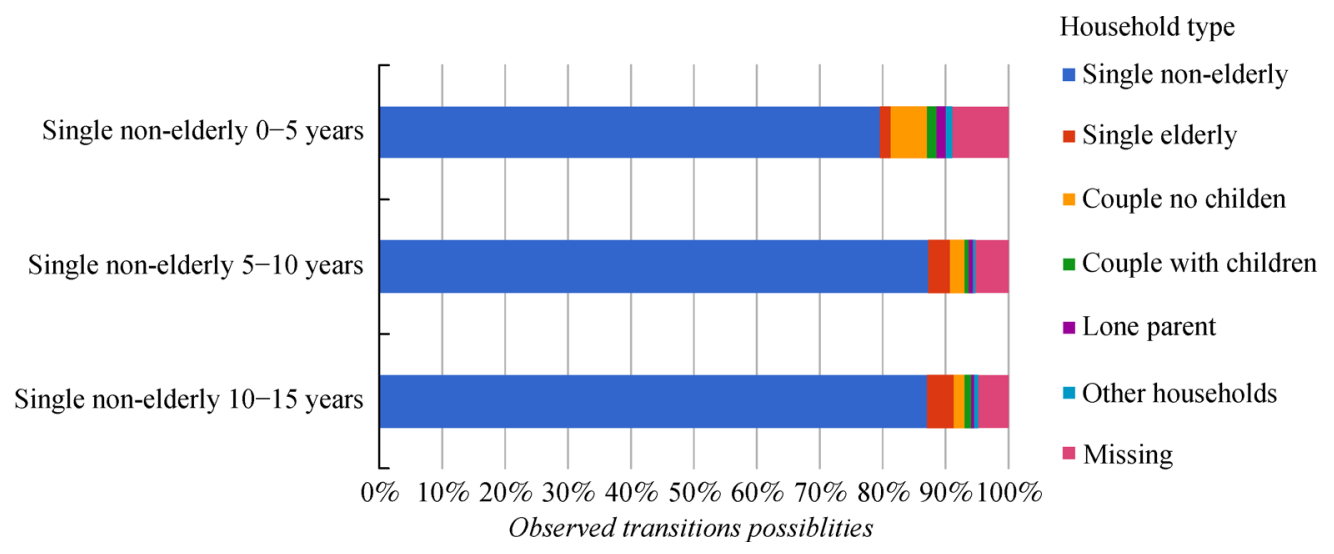

Fig. 2 Observed transition possibilities of single non-elderly households to different family types over 5, 10, and 15 years

occurring inner transition patterns of single non-elderly households over 5,10 , and 15 years.

From 1991 to 1997 , there was a $60 \%$ drop from the initial number of single non-elderly households. On the other hand, the proportion of couple without children, couple with children, and single elderly households increased to reach $84 \%, 51 \%$, and $26 \%$, respectively. This could be explained by the fact that each year, around $20 \%$ of single non-elderly households moved to other household types, of which $6 \%$ were couple without children, $1.8 \%$ single elderly, and 4\% shared among couple with children, other, and lone parent households. Considering the $20 \%$ yearly transition, the decrease in the proportion of single non-elderly households would have been greater, if there were no transition from the other family types to single non-elderly types. For instance, it was found that around $6.5 \%$ of couple without children households transitioned to single non-elderly households.

From 1997 to 2002, the number of single non-elderly and couple without children households decreased by $35 \%$ and $32 \%$, respectively. Conversely, there were $100 \%$ and $40 \%$ increases in the proportion of single elderly and couple with children households, respectively. The decline in the proportion of single non-elderly households was not as significant as in the previous period, as there was a 7.5\% decline in their annual transition rate. In addition to that, 
the rise in the number of single elderly households is due to the increase in yearly transition rate to this family type, from $1.75 \%$ to $3.48 \%$. Similarly, the surge in the proportion of couple with children households was affected by the lack of transition of a considerable proportion of this household type (roughly 93\%) during this period despite the decrease in the transition rates from other household types to this family type.

Finally, between 2002 and 2008, there were no major changes to report from the precedent period with the exception of $20 \%$ and $74 \%$ declines in the percentage of couples without children and single non-elderly households, respectively. Thus, the proportion of couples with children increased between 2002 and 2004, before stabilizing.

\section{Demographic and socioeconomic factors influencing household transition}

Because the dependent variable in this study is dichotomous, binary logistic regression was utilized to help determine the socioeconomic and demographic factors affecting households' demographic evolution, and, subsequently, to predict future transition models. For those reasons, 40 models were developed to cover a period of 10 years, where each model represents a given household transition for a particular year. However, in this paper, we report only on the transitions to couple without children households in the next 5 and 10 years.

As addressed in the methodology section, fixed effects and random effects models were used. First, the fixed effects model was defined using Eq. (1).

$$
\log \left(\frac{P_{i t}}{1-P_{i t}}\right)=\mu_{t}+\beta x_{i t}+y z_{i}+\alpha_{i}
$$

$P_{i t}$ is the probability that $y_{i t}=1$, and $z_{i}$ represents the group of variables describing the households, which does not differ over time. Conversely, $x_{i t}$ depicts the vector of variables that change over time and individuals. $\beta$ and $y$ are vectors of coefficients whereas $\mu_{t}$ is the intercept, which can vary over time. $\alpha_{i}$ represents the differences between householders that are stable over time and those otherwise, based on $z_{i}$. After some algebra has been applied to Eq. (1) and assuming the independence of $y_{i 1}$ and $y_{i 2}$ given any householder $i$ and its $\alpha_{i}$ value, $z_{i}$ and $\alpha_{i}$ will be omitted from the equation as shown in Eq. (2). This will result in the elimination of participants who do not vary with the response variable and the creation of various scores for all time-varying independent variables (Allison, 2006).

$$
\log \left(\frac{\operatorname{Pr}\left(y_{i 1}=0, y_{i 2}=1\right)}{\operatorname{Pr}\left(y_{i 1}=1, y_{i 2}=0\right)}\right)=\left(\mu_{2}-\mu_{1}\right)+\beta\left(x_{i 2}-x_{i 1}\right)
$$

On the other hand, a random effects logistic regression model results in Eq. (3) from the inclusion of a random intercept $\zeta_{\mathrm{j}} \sim \mathrm{N}(0, \psi)$, whose independence from the covariates is assumed.

$$
\begin{aligned}
& \log i t\{\operatorname{Pr}(y i j=1 \mid x i j, \zeta j)\} \\
& \quad=\beta 1+\beta 2 \times 2 j+\beta 3 \times 3 i j+\beta 4 \times 2 j \times 3 i j+\zeta j
\end{aligned}
$$

It should be taken into account that the responses $y i j$ for any householder $j$ and at any given time are independently Bernoulli distributed, which is defined in Eq. (4).

$$
\begin{aligned}
& \pi i j \equiv \operatorname{Pr}(y i j \mid x i j, \zeta j) \\
& \log i t(\pi i j)=\beta 1+\beta 2 x 2 j+\beta 3 \times 3 i j+\beta 4 \times 2 j \times 3 i j+\zeta j \\
& y i j \mid \pi i j \sim \operatorname{Binomial}(1, \pi i j)
\end{aligned}
$$

Finally, to select the right type of model, the Hausman specification test was used. The null hypothesis $\mathrm{H} 0$ was that a random effects model is appropriate, whereas the alternative hypothesis $\mathrm{H} 1$ suggested that a fixed effects model is suitable.

5.1 Results of transition to couple without children household in 5 and 10 years

Table 1 and Table 2 illustrate the logistic regression models pertaining to transitions to couple without children households in the next 5 and 10 years. Overall, it is evident that the type and number of significant independent variables were not consistent across the two models. Furthermore, the models' independent variables explained $22 \%$ and $15 \%$ of the total variation in the dependent factor (transition to couple without children) in year 5 and year 10 , respectively.

\subsubsection{Year 5}

First, analysis of the first model of transition (1) suggests that the odds ratios for couple with children and separated households were 4.230 and 6.343 , respectively. This could be attributed to the fact that separated householders usually remained apart for between 2 to 3 years before reuniting or divorcing and consequently embarking on a new relationship, according to a recent report on divorce in England and Wales (ONS, 2013a). Similar findings were also reported for the US by Bramlett and Mosher (2012). Apart from these variables, the odds ratios of being a couple without children in 5 years were 7.456 and 8.086, for households living in purpose-built and converted flats, respectively. This could be attributed to the fact that over $50 \%$ of the UK cohabiting couples prefer to live together at least 5 years before the birth of their first child, and hence prefer to remain in flats (Goodman and Greaves, 2010). Similarly, the odds ratio was also higher by a factor of 1.856 for households in semi-detached houses. This finding is considered valid since these dwelling types are very popular with middle-income households, who are 
Table 1 Part a: Transition models to couple without children household in the next 5 and 10 years

\begin{tabular}{|c|c|c|c|c|}
\hline \multirow{2}{*}{ Variables } & \multicolumn{2}{|c|}{5 years transition model } & \multicolumn{2}{|c|}{10 years transition model } \\
\hline & Odds ratio & $95 \% \mathrm{CI}$ & Odds ratio & $95 \% \mathrm{CI}$ \\
\hline \multicolumn{5}{|l|}{ Household characteristics } \\
\hline \multirow[t]{2}{*}{ Couple with children } & $4.230 * *$ & $1.97-9.07$ & 2.891 & $0.623-13.4$ \\
\hline & $(1.617)$ & & $(2.264)$ & \\
\hline \multirow[t]{2}{*}{ Age of the householder } & $1.1^{* *}$ & $1.08-2.82$ & $1.551 * * *$ & $1.40-1.708$ \\
\hline & $(0.0285)$ & & $(0.0767)$ & \\
\hline \multicolumn{5}{|l|}{ Householder marital status } \\
\hline \multirow[t]{2}{*}{ Never married } & 1.986 & $0.75-5.20$ & 0.900 & $0.58-4.62$ \\
\hline & $(0.977)$ & & $(0.8798)$ & \\
\hline \multirow[t]{2}{*}{ Divorced } & 0.659 & $0.26-1.7$ & - & - \\
\hline & $(0.318)$ & & & \\
\hline \multirow[t]{2}{*}{ Separated } & $6.343^{*}$ & $1.49-26.8$ & 0.4158 & \\
\hline & $(4.667)$ & & $(0.3825)$ & \\
\hline \multicolumn{5}{|c|}{ Employment mode and socioeconomic status } \\
\hline \multirow[t]{2}{*}{ Higher-grade professionals } & $0.455^{*}$ & $0.22-0.92$ & $0.304 * *$ & $0.12-0.72$ \\
\hline & $(0.164)$ & & $(0.135)$ & \\
\hline \multirow[t]{2}{*}{ Lower-grade professionals } & 0.560 & $0.29-1.07$ & $0.269 * *$ & $0.11-0.63$ \\
\hline & $(0.187)$ & $0.17-0.53$ & $(0.119)$ & \\
\hline \multirow[t]{2}{*}{ Routine non-manual employees } & $0.431^{*}$ & $0.17-1.06$ & 0.491 & $0.156-1.53$ \\
\hline & $(0.198)$ & $0.15-0.69$ & $(0.286)$ & \\
\hline \multirow[t]{2}{*}{ Foreman and technicians } & $0.384 * *$ & $0.15-0.98$ & 0.226 & $0.05-1.11$ \\
\hline & $(0.184)$ & & $(0.184)$ & \\
\hline \multirow[t]{2}{*}{ Semi-unskilled manual workers } & $0.227 *$ & $0.106-1.89$ & 0.450 & $0.08-1.44$ \\
\hline & $(0.132)$ & & $(0.331)$ & \\
\hline \multirow[t]{2}{*}{ Small proprietors with employees } & - & - & 0.105 & $0.01-1.10$ \\
\hline & & & $(0.126)$ & \\
\hline
\end{tabular}

Note: CI: confidence interval; standard errors in parentheses. *Significance at the $90 \%$ level; **Significance at the $95 \%$ level; ***Significance at the $99 \%$ level.

mostly couples without and with children (ONS, 2015a; WhatPrice, 2017). Householder age not only had a significant positive effect but also its odds ratio (1.1) was consistent with previous models. After a closer inspection of this result using an age group variable instead, it was found that for householders aged 26 and 36, the odds ratio for becoming a couple without children was higher by a factor of 1.745. Indeed, this aligns with the Births by Parents' Characteristics in England and Wales report, which suggests that the average age of couples with children was 31.6 years at the time of their first child's birth (ONS, 2015b).

In contrast, for households in the socioeconomic classes of higher-grade professional, routine non-manual, foreman/technicians, and semi-unskilled manual workers, the odds of transitioning to couple without children households in the next 5 years were lower by $54.5 \%, 56.9 \%$, $61.6 \%$, and $77.2 \%$, respectively. This could be because around $45 \%$ of households from these socioeconomic classes prefer to have at least 1-2 children given their financial stability (Whiting, 2010). In addition to that, for households working full-time, the odds ratio for being couples without children in 5 years was lower by $54.1 \%$. This could be interpreted in two distinct ways. The first argument advises that households with full-time jobs have more income stability (JRF, 2005). Because of that, they are more willing and prepared to have children. The second possible interpretation, however, might be related to the fact that some future parents (planning to have children) prefer to work part-time to avoid paying the prohibitive annual childcare cost of $11,000 £$ on average according to NCT (2014). Indeed, around 55\% of women with dependent children are employed part-time (ONS, 2014). As expected, the odds ratios of variables related to tenure mode, namely renting from local authorities and from private landlords, were 0.129 and 0.317 , respectively. These findings were in a good agreement with the UK recent official report on home ownership and renting 
Table 2 Part b: Transition models to couple without children household in the next 5 and 10 years

\begin{tabular}{|c|c|c|c|c|}
\hline \multirow{2}{*}{ Variables } & \multicolumn{2}{|c|}{5 years transition model } & \multicolumn{2}{|c|}{10 years transition model } \\
\hline & Odds ratio & $95 \% \mathrm{CI}$ & Odds ratio & $95 \% \mathrm{CI}$ \\
\hline \multicolumn{5}{|l|}{ Dwelling and tenure type } \\
\hline \multirow[t]{2}{*}{ Living in a purpose-built flat } & $7.456^{* * *}$ & $2.46-22.57$ & 0.7568 & \\
\hline & $(4.214)$ & & $(0.7241)$ & \\
\hline \multirow[t]{2}{*}{ Living in a semidetached house } & $1.856^{*}$ & $1.012-3.400$ & 0.463 & $0.75-4.68$ \\
\hline & $(0.573)$ & & $(0.284)$ & \\
\hline \multirow[t]{2}{*}{ Living in a converted flat } & $8.086^{* *}$ & $1.89-34.50$ & 1.6932 & \\
\hline & $(5.987)$ & & $(2.1283)$ & \\
\hline \multirow[t]{2}{*}{ Dwelling owned with mortgage } & 0.517 & $0.262-1.019$ & 0.551 & $0.235-1.29$ \\
\hline & $(0.179)$ & & $(0.239)$ & \\
\hline \multirow[t]{2}{*}{ Dwelling rented from local authorities } & $0.129 *$ & $0.021-0.778$ & 0.0632 & $0.0045-0.88$ \\
\hline & $(0.118)$ & & $(0.0850)$ & \\
\hline \multirow[t]{2}{*}{ Dwelling rented from private landlords } & $0.317 *$ & $0.093-1.072$ & 0.425 & $0.08-2.22$ \\
\hline & $(0.197)$ & & $(0.358)$ & \\
\hline \multicolumn{5}{|l|}{ Household income } \\
\hline \multirow[t]{2}{*}{ On pension } & $4.254 * *$ & $1.479-12.22$ & 1.7955 & \\
\hline & $(2.292)$ & & $(1.6206)$ & \\
\hline \multirow[t]{2}{*}{ Square root of annual gross income } & 1.005 & $0.998-1.011$ & - & - \\
\hline & $(0.00329)$ & & & \\
\hline \multirow[t]{2}{*}{ Square root of total benefit income } & $0.988 * *$ & $0.979-0.9955$ & $0.997 *$ & $0.98-1.005$ \\
\hline & $(0.00407)$ & & $(0.00456)$ & \\
\hline \multirow[t]{2}{*}{ Working full-time } & $0.459^{*}$ & $0.241-0.875$ & 1.4626 & \\
\hline & $(0.151)$ & & $(0.6469)$ & \\
\hline Observations & 1251 & & 662 & \\
\hline Number of PID (households) & 125 & & 99 & \\
\hline Type of model & Fixed effects & & Fixed effects & \\
\hline McFadden's $R^{2}$ & 0.22 & & 0.150 & \\
\hline
\end{tabular}

Note: CI: confidence interval; standard errors in parentheses. ${ }^{*}$ Significance at the $90 \%$ level; ${ }^{* *}$ Significance at the $95 \%$ level; ***Significance at the $99 \%$ level.

(ONS, 2013b). Finally, the square root of total annual benefit income was significant but had minor effect, whereas the $\log 10$ of household annual gross income was insignificant.

Other insignificant variables include; other households, lone parent, widowed, divorced, never married, living in terraced houses, dwelling size. Moreover, the following socio-economic classes namely; farmers-small holders, small proprietors with employees, small proprietors without employees, and lower-grade professionals.

\subsubsection{Year 10}

In comparison to Year 5 model, examination of the model representing the transition possibilities to couple without children households in the next 10 years has suggested the insignificance of some variables, namely never married and semi-unskilled manual workers. This, in turn, indicates that the data set could not capture the transitions of never married households as well as households with semiunskilled manual workers beyond 10 years.

On the other hand, for one additional year on the householder age, the odds ratio for being a couple without children after 10 years was higher by $55 \%$. Conversely, for higher- and lower-grade professionals, the odds ratios for becoming couples without children in 10 years were lower by $69.6 \%$ and $73.1 \%$, respectively. The odds ratio of the square root total benefit income, however, was relatively stable (lower by $0.3 \%$ ) in comparison to the previous model.

Finally, the variables of on pension, working full-time, living in purpose-built flats, living in converted flats, separated, divorced, widowed, owned with mortgage, renting from private landlord, and renting from local authorities were not statistically significant. 


\section{Impact of household transitions on household annual electricity and gas consumption}

Point-biserial correlation was used to determine the strength and direction of relationship between the predicted transition variables and energy consumption variables. Even though it is considered a unique case of Pearson product moment correlation, point-biserial correlation can be handled by any statistical package, such as SPSS, R, or Stata (Kornbrot, 2005). Eq. (5) illustrates the calculation of the correlation coefficient $r_{p b}$.

$$
r_{p b}=\frac{\bar{Y}_{1}-\bar{Y}_{0}}{\bar{S} y} \sqrt{\frac{N_{1} N_{0}}{N(N-1)}}
$$

$Y_{0}$ and $Y_{1}$ are the means of observations coded 0 and 1 , respectively; $N_{0}$ and $N_{1}$ are the number of observations coded 0 and 1 , respectively; $N$ is the total number of observations; and $S_{y}$ is the standard deviation of the observation.

\subsection{Findings}

For simplification purposes, only the impact of transitions to couple without children household on annual energy consumption will be addressed. Table 3 depicts the correlation matrix between household annual energy consumption variables and couple without children transition variables. First, it is evident that the resulting correlations were not significant across the 10 years. More precisely, this applies to the correlations between log 10 annual electricity consumption and transitions in the 9th and 10th years and those between the square root of annual gas consumption and the 6th year of transition. However, all significant associations were at the $99 \%$ level and their direction was mostly positive with the exception of year 6 .

6.2 Mapping of estimated energy figures onto transition patterns of single non-elderly households

A possibility for our developed concept is to forecast the residential energy consumption in relation to different household transitions over their life cycle. Therefore, we present in Fig. 3 an example showing the variation in energy usage patterns of single non-elderly households during their transitions to other family types after 5 years.

Overall, analysis of the findings indicated that the transition probabilities from single non-elderly to couple without children, couple with children, lone parents, single elderly, and other households after 5 years were $19.9 \%$, $12.1 \%, 3.1 \%, 46.7 \%$, and $1.7 \%$, respectively. For the majority of households transitioning to single elderly in 5 years, $67.5 \%$ should consume between 1000 and $3000 \mathrm{~kW} \cdot \mathrm{h}$ electricity annually. On the other hand, of those that become couple without children households, $4.76 \%, 42.85 \%$, and $26.19 \%$ are expected to consume less than $1000 \mathrm{~kW} \cdot \mathrm{h}, 1000-3000 \mathrm{~kW} \cdot \mathrm{h}$, and 3000 $4000 \mathrm{~kW} \cdot \mathrm{h}$, respectively. As for the majority of households transitioning to couple with children status (53\%), their use should be between 2000 and $4000 \mathrm{~kW} \cdot \mathrm{h}$ annually, whereas $19.6 \%$ should consume more than $5000 \mathrm{~kW} \cdot \mathrm{h}$. Concerning households making transitions to lone parent households, around 57\% should use 2000 $4000 \mathrm{~kW} \cdot \mathrm{h}$, whereas the remaining should use more than $5000 \mathrm{~kW} \cdot \mathrm{h}$ per year. Interestingly, the annual electricity consumption of the majority of those who remained single non-elderly households after 5 years and consumed between 1000 and $4000 \mathrm{~kW} \cdot \mathrm{h}$ should increase by an average of $1.02 \%$. Conversely, for those who consumed $4000-5000 \mathrm{~kW} \cdot \mathrm{h}$ and more than $5000 \mathrm{~kW} \cdot \mathrm{h}$, a decrease of $1.1 \%$ and $3 \%$, respectively, is expected.

\section{EvoEnergy urban energy model}

\subsection{Overview and functionalities}

EvoEnergy is currently being developed at the Creative and Virtual Technologies Laboratory at Nottingham Trent University in collaboration with the Nottingham Energy Partnership. The main intention behind EvoEnergy was to offer an integrated and smart platform that supports energy planners in their sustainable energy planning decision-

Table 3 Impact of couple without children household transitions on annual gas and electricity consumption

\begin{tabular}{|c|c|c|c|c|c|c|c|c|c|c|}
\hline & $\mathrm{CN} 1$ year & $\mathrm{CN} 2$ years & $\mathrm{CN} 3$ years & $\mathrm{CN} 4$ years & CN 5 years & $\mathrm{CN} 6$ years & $\mathrm{CN} 7$ years & $\mathrm{CN} 8$ years & CN 9 years & $\mathrm{CN} 10$ years \\
\hline $\begin{array}{l}\text { Log } 10 \text { annual } \\
\text { electricity } \\
\text { usage }\end{array}$ & $0.11^{* * *}$ & $0.093^{* 3 / 2}$ & $0.098^{\text {*F }}$ & $0.094^{3 * \pi}$ & $0.08^{* * \pi}$ & $-.034^{3 * \pi}$ & $0.04^{* * \pi}$ & $0.03^{* * \pi}$ & 0.02 & 0.008 \\
\hline Sig. (2-tailed) & 0.000 & 0.000 & 0.000 & 0.000 & 0.000 & 0.005 & 0.000 & 0.006 & 0.074 & 0.538 \\
\hline $\begin{array}{l}\text { Square root } \\
\text { of annual } \\
\text { gas usage }\end{array}$ & $0.114^{* *}$ & $0.091^{* *}$ & $0.068^{* *}$ & $0.057^{* *}$ & $0.05^{* *}$ & $-0.09^{* *}$ & 0.013 & 0.001 & -0.008 & -0.010 \\
\hline Sig. (2-tailed) & 0.000 & 0.000 & 0.000 & 0.000 & 0.000 & 0.000 & 0.290 & 0.930 & 0.553 & 0.419 \\
\hline $\mathrm{N}$ & 6700 & 6700 & 6700 & 6700 & 6700 & 6700 & 6700 & 6700 & 6700 & 6700 \\
\hline
\end{tabular}

Note: CN, Couple without children; *Significance at the $95 \%$ level; **Significance at the $99 \%$ level; Sig., Level of significance. 


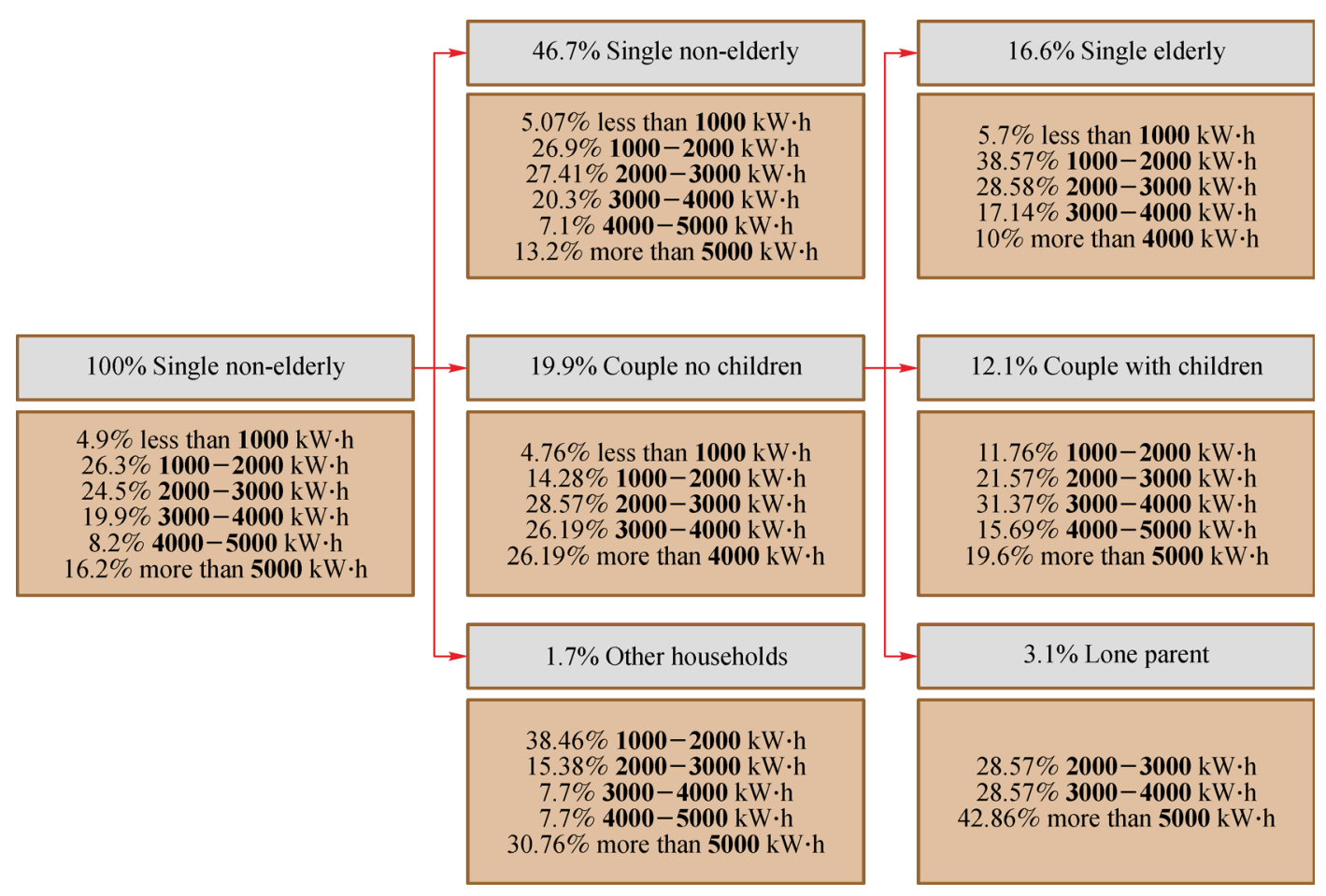

Fig. 3 Expected annual electricity consumption figures of single non-elderly households before and after their transition to different family types in 5 years

making, especially given the imposed strict $\mathrm{CO}_{2}$ emission reduction targets. More specifically, the intended abilities of this platform are as follows.

- Identify residential areas with potential for $\mathrm{CO}_{2}$ emission reduction

- Help urban planners choose the most effective strategies (e.g., retrofit and technology upgrade) based on each scenario

- Assess the degree of improvement in energy usage/ $\mathrm{CO}_{2}$ emissions after implementing certain measures

- Predict the energy usage from the single consumer to the city level in the next 10 years as a function of change in households' socioeconomic circumstances and their life cycle demographic transitions

In addition, another future goal of this platform is to empower and engage young communities with the goal of encouraging them to reduce their energy usage. For these reasons and for others related to the growing interest and recognition of gaming in urban planning (Skelton, 2013), we have decided to use a well-known game engine as the main platform for hosting EvoEnergy. To the best of our knowledge, we are the first to utilize the capabilities of game engines to support urban energy planning decisionmaking. However, the 3-D modeling of residential buildings in EvoEnergy was performed according to CityGML standards. CityGML is a standard international format for representing, storing, and sharing 3-D city model data. It provides the standard mechanisms that govern the description of different 3-D objects in relation to their geometry, semantics, and topology. The advantage of CityGML over other 3-D city model formats lies in its flexible level of detail (LOD) (Krüger and Kolbe 2012).

\subsection{Main components}

In light of the above, EvoEnergy comprises four main modules, as is shown in Fig. 4. The first module, which is known as "Dwelling physical and thermal characteristics," encompasses physical information, such as dwelling age, type, and size. Furthermore, it includes information on the nature of a dwelling's HVAC system (e.g. combi-boiler), HVAC controls, insulation, SAP rating, and bills inclusion. The second part, which is known as "Household socioeconomic characteristics," contains demographic and socioeconomic information, including the following factors: different income types (e.g. pension), household size, children dependency, householder age, marital status, household type, level of education, socioeconomic class, tenure mode, and others. It should be noted that these two modules were designed to work in a complementary manner to preserve the integrity of the overall system. The third module enables consultation of the past energy usage trends of particular households at different granularities (e.g. monthly). Moreover, it allows comparison at different periods or with different users. Finally, the fourth module, which is the "Household transition" module, permits the prediction of future transition probabilities to different 


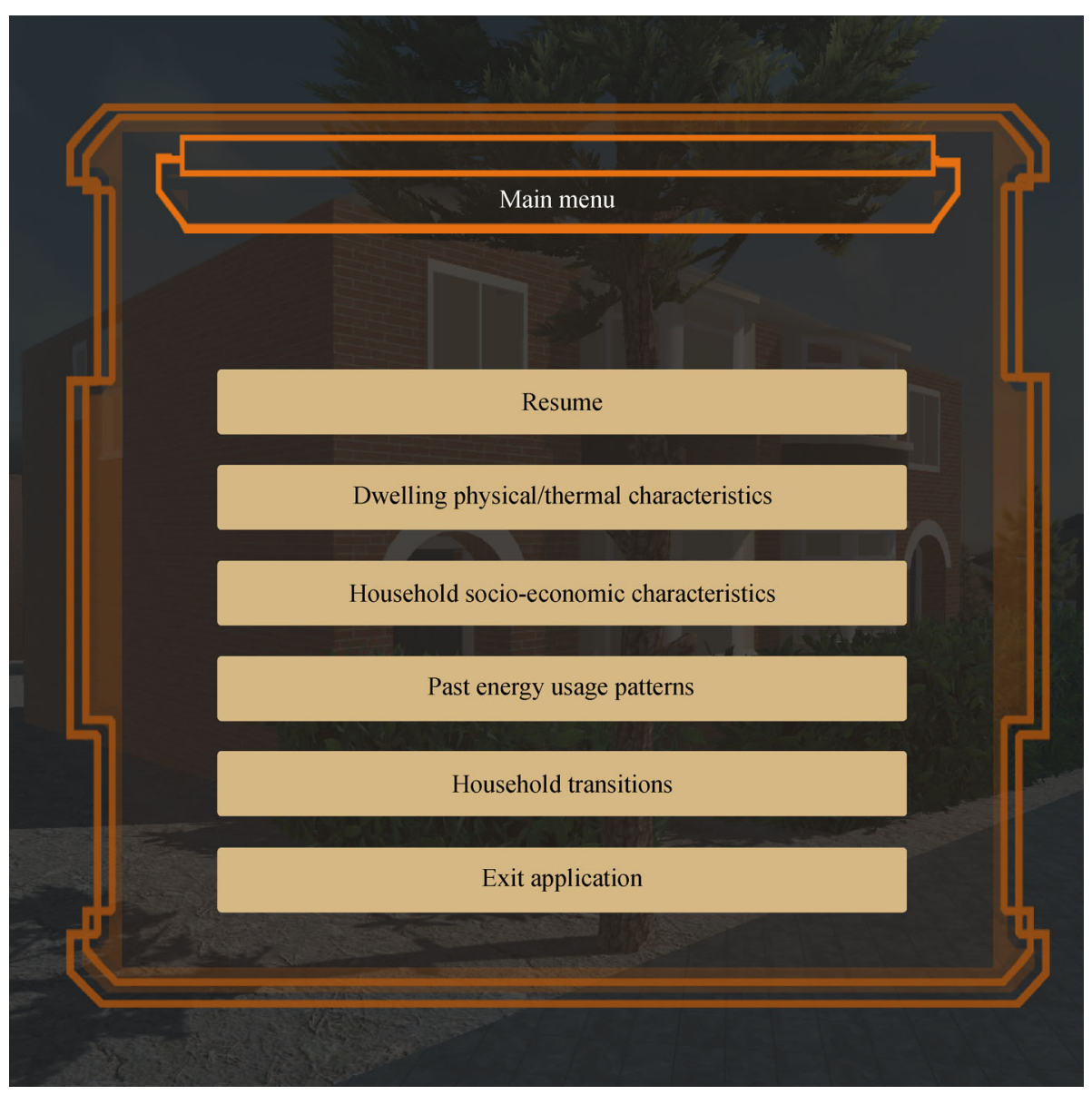

Fig. 4 Main components of EvoEnergy

household types. Moreover, it enables the estimation of annual gas and electricity consumption figures based on the physical and socioeconomic modules as well as the predicted transitions.

\subsection{Modus operandi}

As soon as the application is launched, a 3-D model of a particular area is shown (Fig. 5). The user has the option to walk through this area and select a particular dwelling(s) or perform a sematic query from the existing database by directly typing the address and postcode of a given dwelling. Once the user hovers over a particular house, it will be highlighted with a red selection box. Moreover, a summary of the household energy usage history as well as a basic socioeconomic profile, will pop-up (Fig. 6). For further details and operations (e.g., editing and prediction), the user needs to access the main menu, which contains the four modules described previously.

Upon launching the first two modules (physical and socioeconomic), a wide range of information on the envisaged household(s) is retrieved from the main database (Fig. 7). However, the user cannot select nor edit this unless they possess a permission password to do so. To consult the energy usage history of the selected occupant (s), the third module has to be employed. Once accessed, it is possible to choose between two different granularities, namely monthly and quarterly; specify the period to be covered by this module (past year, past 5 years, etc.); and perform comparisons between different dwellings (Fig. 8). This can be extremely useful in cases where the energy patterns of dwellings with similar physical properties and household characteristics are compared. In this way, it is possible to determine the effect of household behavior on energy consumption. Currently, we are working on feeding smart meter data into this module in order to enable finer granularities, which could attain 15-min temporal resolution.

The fourth module, which incorporates the powerful concept of household life cycle transitions, offers the potential to predict the demographic transition probabilities to different household types by simply clicking on one of the household clip arts and specifying the envisaged year of prediction on the timeline slider, as is shown in Fig. 9. This, in turn, will map the energy usage based on the change in the socioeconomic characteristics of the household following this prediction. Finally, the urban energy prediction sub-module allows a meaningful 


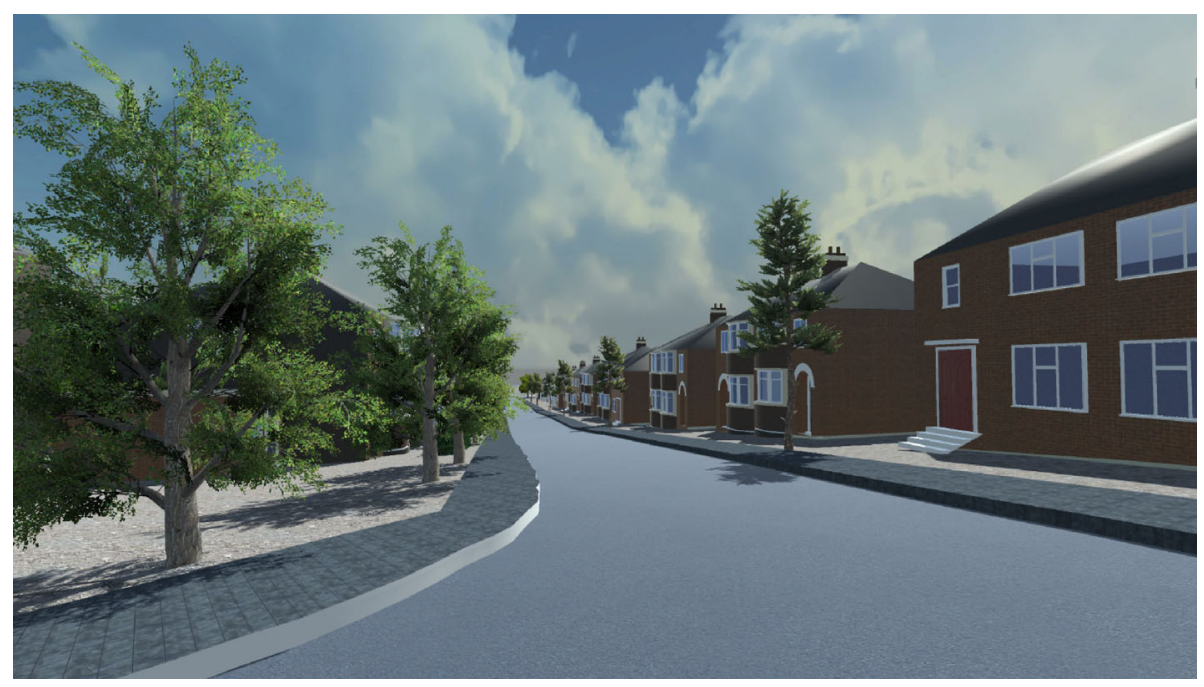

Fig. 5 3-D model of the Sneinton residential area in EvoEnergy

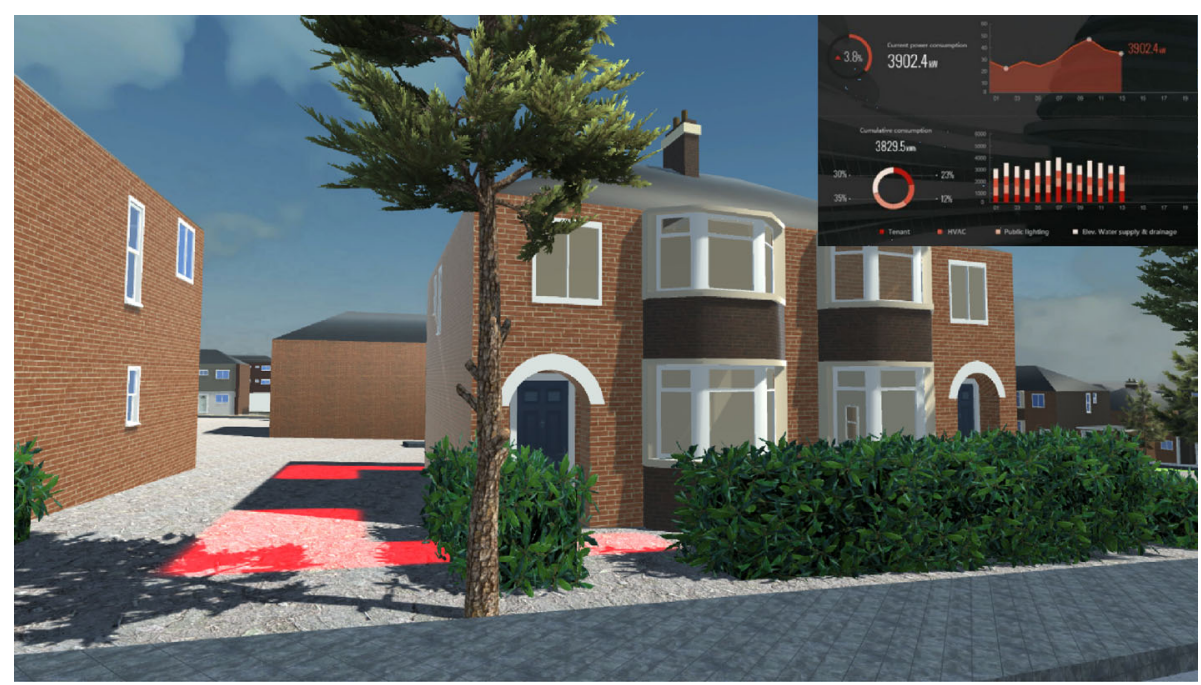

Fig. 6 Summary of a particular household energy usage and socioeconomic profile on mouse hover

comparison between the future transition patterns as well as estimated annual energy patterns of different households over a given period (e.g., 5 years), as is depicted in Fig. 10.

\section{Conclusions}

Conducting this research has enabled us to develop new knowledge on the nature and degree of effect of household demographic evolution on the domestic consumption patterns of the households in the next 10 years. We first began by examining the previous transition patterns of single non-elderly households in the BHPS data set for the period between 1991 and 2008. This has supplied a general understanding of the transition mechanisms related to this household type before analyzing the influencing demographic and socioeconomic factors. However, considering the exploratory nature of this study and the large number of developed transition models (40 models), it was not possible to report every single model herein. Instead, we focused on the transition to couple without children households in the next 5 and 10 years. Following this phase, analysis of the point-biserial correlation coefficients showed a weak association between household transitions and energy usage patterns. However, except the transitions to lone parent households, which are not addressed in this article, these correlations were mostly positive for both gas and electricity. This is in line with recent UK official reports suggesting that a large proportion of this household type is living under consistent fuel poverty as a result of 


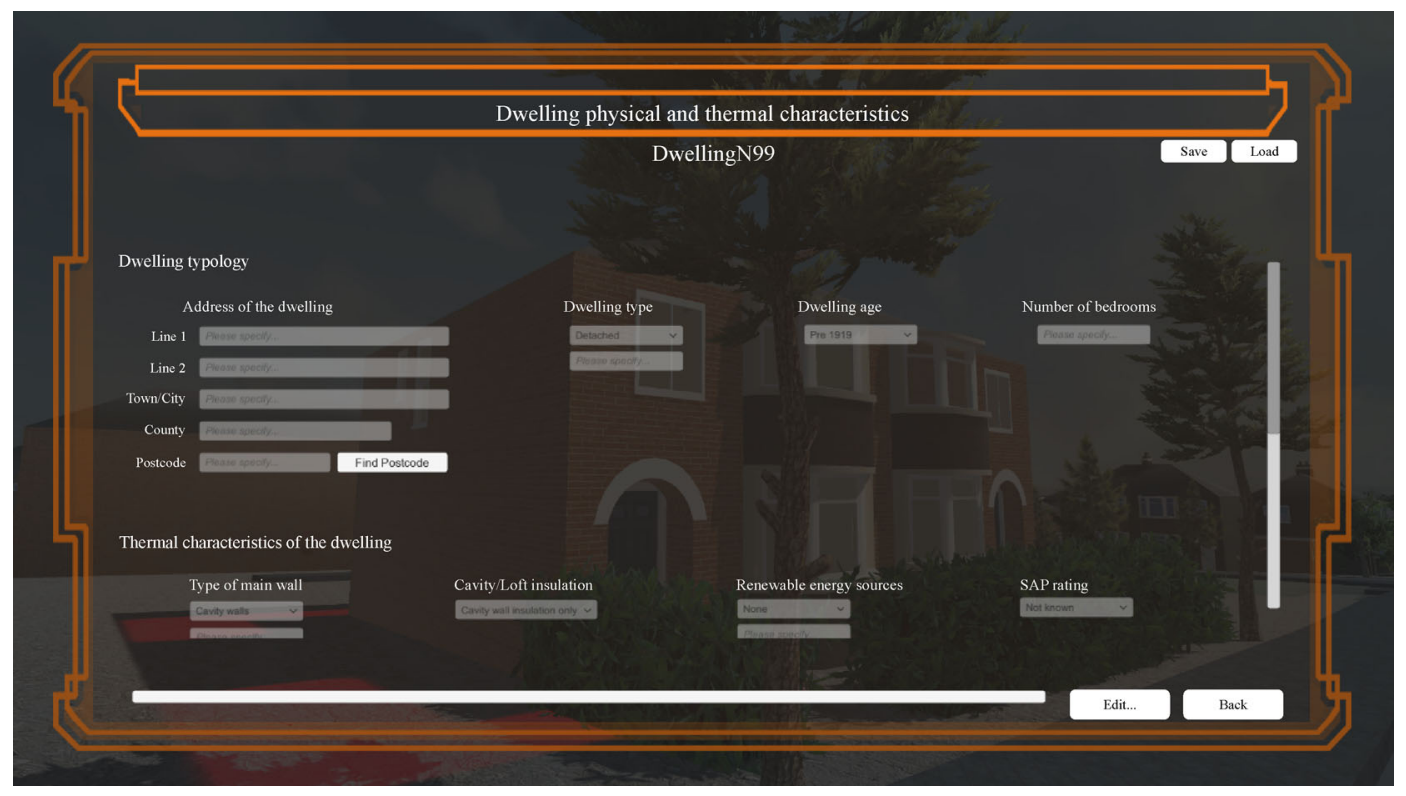

Fig. 7 Snapshot taken of the EvoEnergy Physical module

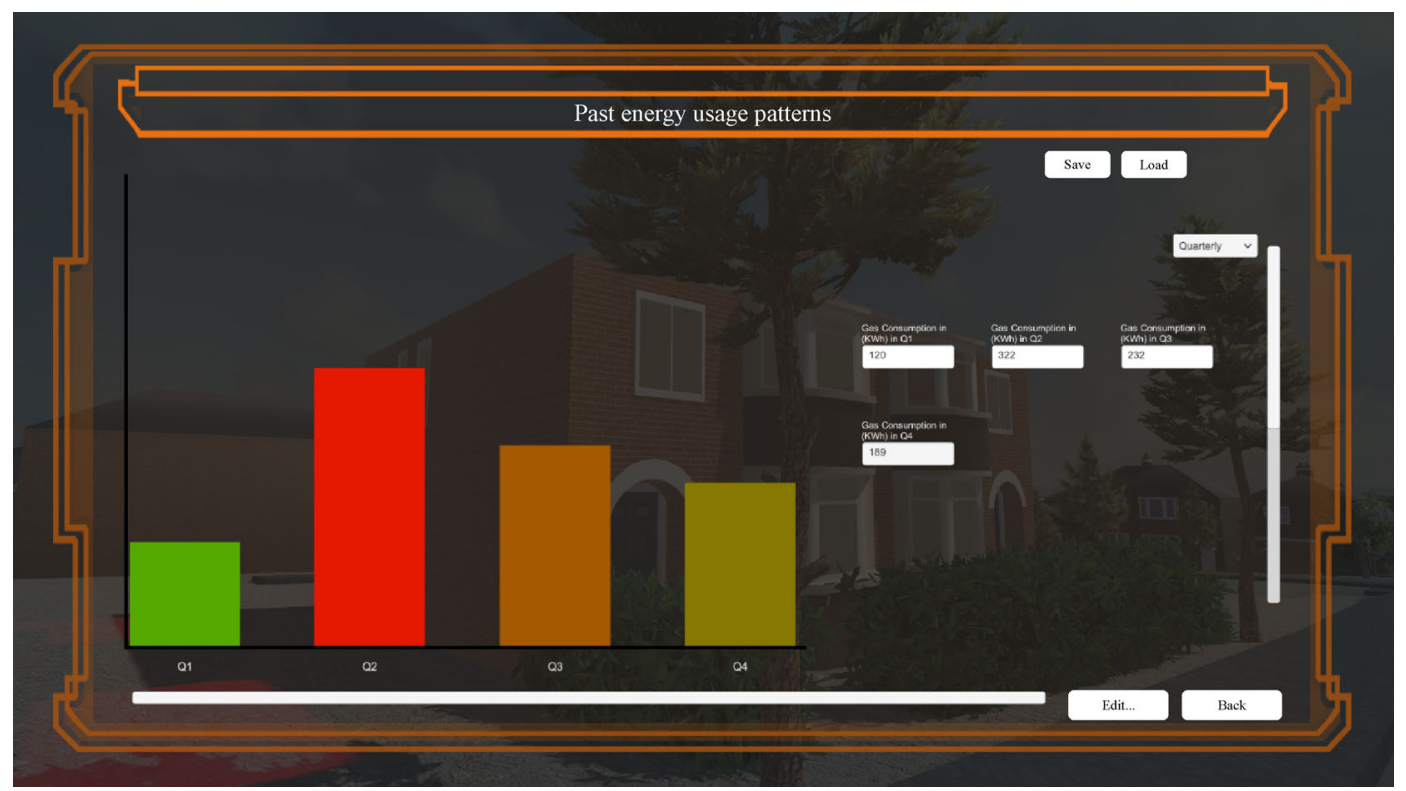

Fig. 8 EvoEnergy past energy history module

low income (DECC, 2015c).

We argue that our research is innovative in that it incorporates the powerful concept of household life cycle into urban energy planning. In addition to that, we think that this will not only enhance the process of demographic projection in new urban areas but also will enable urban planners to forecast as well as monitor residential energy consumption from the single consumer to the city level. This, in turn, will allow for smarter management of the distribution network. To support these arguments, we presented our smart urban energy model EvoEnergy, highlighted its components, and explained its modus operandi. This tool, which was benchmarked in the area of Sneinton in Nottingham on 500 homes, produced very satisfactory predictions. However, this does not mean that it cannot be utilized for larger neighborhoods as well. In fact, this is possible but has its challenges, which include processing time and data storage. For those reasons, the tool will be further developed to accommodate the city of Nottingham using a, zoning approach. In addition to this, it will take into account the zones of energy supply to assess whether a specific supply is sufficient for a given zone. 


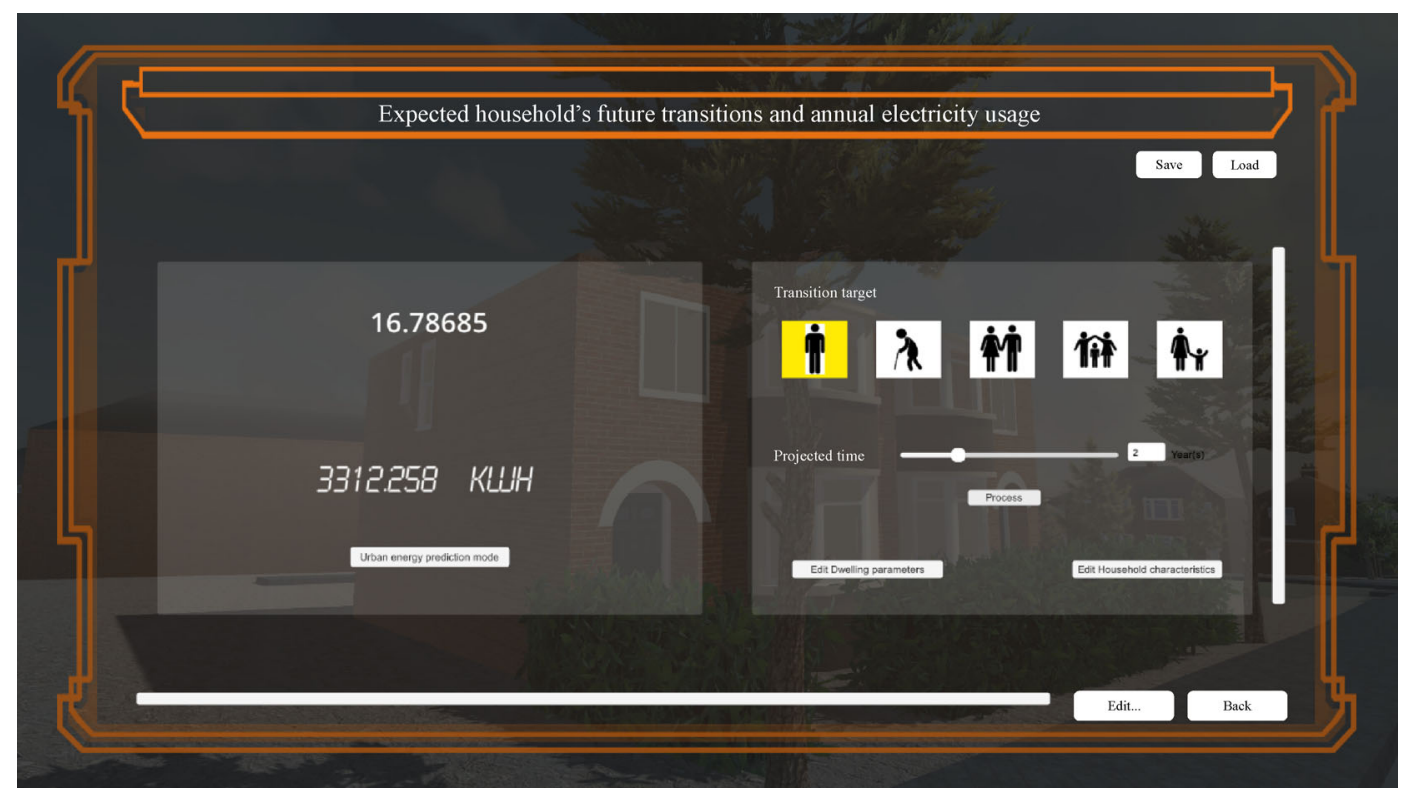

Fig. 9 Household life cycle transition and energy prediction module (dwelling mode)

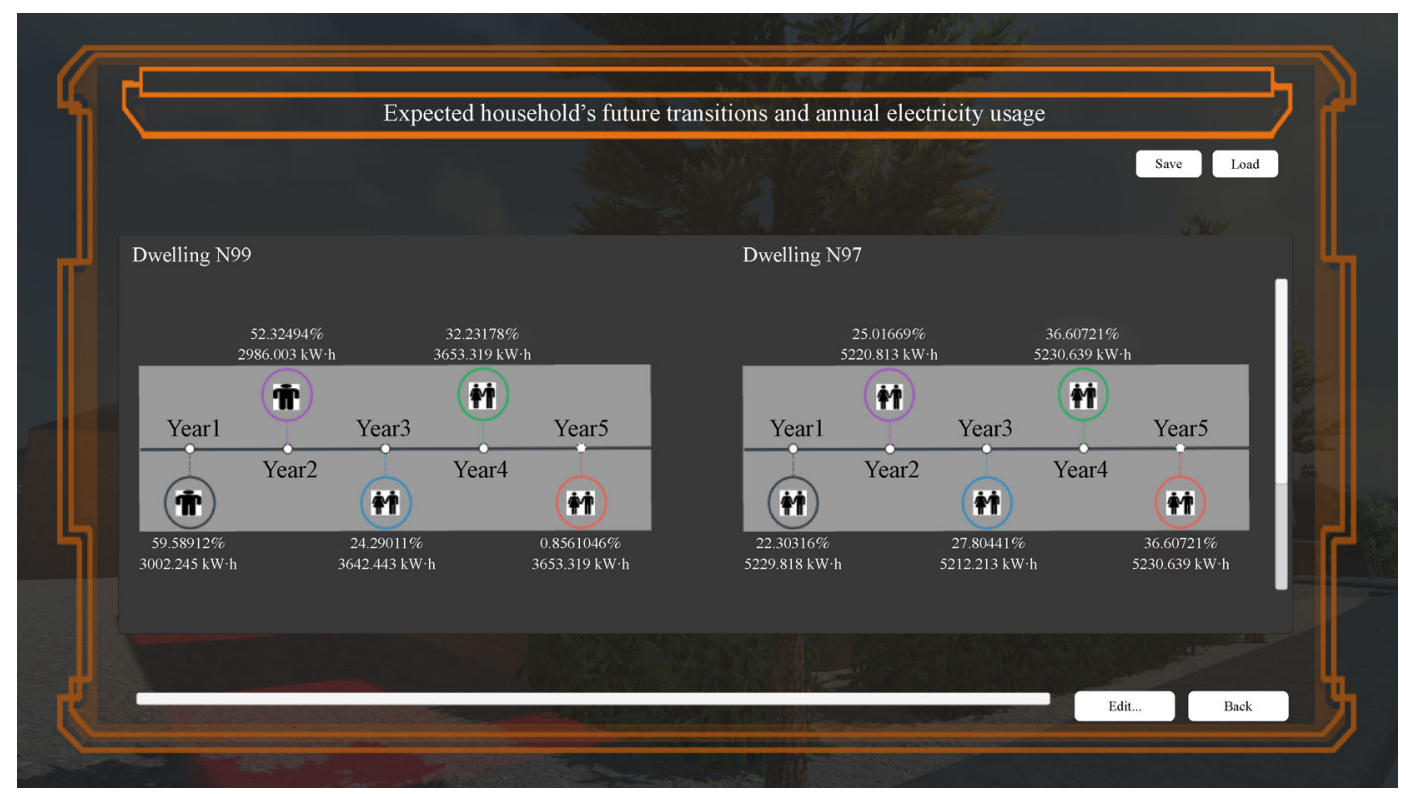

Fig. 10 Household lifecycle transition and energy prediction module (urban energy prediction mode)

Finally, one advantage of our approach is its applicability to different countries that possess household panel data, such as Germany.

\section{References}

Allison P D (2006). Fixed effects regression methods in SAS. Thirty-first Annual SAS. https://www.researchgate.net/profile/Paul_Allison/publication/228767539_Fixed_effects_regression_methods_in_SAS/ links/0fcfd50e5de875b37b000000.pdf
Bartiaux F, Gram-Hanssen K (2005). Socio-political factors influencing household electricity consumption: A comparison between Denmark and Belgium. ECEE 2005 Summer Study, 1313-1325

Bramlett M D, Mosher W D (2012). Cohabitation, marriage, divorce, and remarriage in the United States. Vital health statistics, 23(22): 132

Brounen D, Kok N, Quigley J M (2012). Residential energy use and conservation: Economics and demographics. European Economic Review, 56(5): 931-945

CIA (2015). The world factbook. https://www.cia.gov/library/publications/the-world-factbook/fields/2212.html 
DECC (2015a). Energy Consumption in the UK (2015). https://www. gov.uk/government/uploads/system/uploads/attachment_data/file/ 449102/ECUK_Chapter_1_-_Overall_factsheet.pdf

DECC (2015b). RPI: fuel \& light: electricity (Jan 1987=100) - Office for National Statistics. https://www.ons.gov.uk/economy/inflationandpriceindices/timeseries/dobx.

DECC (2015c). Annual Fuel Poverty Statistics Report

Druckman A, Jackson T (2008). Household energy consumption in the UK: A highly geographically and socio-economically disaggregated model. Energy Policy, 36(8): 3177-3192

Du R Y, Kamakura W A (2006). Household life cycles and lifestyles in the United States. Journal of Marketing Research, 43(1): 121-132.

Frederiks E R, Stenner K, Hobman E V (2015). The socio-demographic and psychological predictors of residential energy consumption: A comprehensive review. Energies, 8(1): 573-609

Genjo K, Tanabe S I, Matsumoto S I, Hasegawa K, Yoshino H (2005). Relationship between possession of electric appliances and electricity for lighting and others in Japanese households. Energy and Building, 37(3): 259-272

Gill Z M, Tierney M J, Pegg I M, Allan N (2010). Low-energy dwellings: The contribution of behaviours to actual performance. Building Research and Information, 38(5): 491-508

Goodman A, Greaves E (2010). Cohabitation, marriage and child outcomes. http://www.ifs.org.uk/comms/comm114.pdf

Greene W W H (2012). Econometric analysis. 97

Guerra Santin O, Itard L, Visscher H (2009). The effect of occupancy and building characteristics on energy use for space and water heating in Dutch residential stock. Energy and Buildings, 41(11): 1223-1232

Hoaglin D C, Iglewicz B, Tukey J W (1986). Performance of some resistant rules for outlier labeling. Journal of the American Statistical Association, 81(396): 991-999

ISER (2016). British Household Panel Survey (BHPS) - Institute for Social and Economic Research (ISER). https://www.iser.essex.ac.uk/ bhps

JRF (2005). The effect of parents' employment on outcomes for children JRF. https://www.jrf.org.uk/report/effect-parents-employment-outcomes-children

Kornbrot D (2005). Point biserial correlation. Wiley StatsRef: Statistics Reference Online

Krüger A, Kolbe T H (2012). Building Analysis for Urban Energy Planning using Key Indicators on Virtual 3D City Models - the Energy Atlas of Berlin. In: International Archives of Photogrammetry, Remote Sensing and Spatial Information Sciences, XXII Congress of the International Society for Photogrammetry and Remote Sensing (ISPRS), Melbourne

Longhi S (2014). Residential energy use and the relevance of changes in household circumstances. ISER Working Paper Series
Mansouri I, Newborough M, Probert D (1996). Energy consumption in UK households: Impact of domestic electrical appliances. Applied Energy, 54(3): 211-285

NCT (2014). Barriers remain for parents returning to work. https://www. nct.org.uk/press-release/barriers-remain-parents-returning-work

ONS (2013a). Divorces in England and Wales: 2013. http://www.ons. gov.uk/peoplepopulationandcommunity/birthsdeathsandmarriages/ divorce/bulletins/divorcesinenglandandwales/2013\#children-ofdivorced-couples

ONS (2013b). Home ownership and renting in England and Wales detailed characteristics

ONS (2014). Families in the labour market. http://webarchive.nationalarchives.gov.uk/20160105160709/http://www.ons.gov.uk/ons/ dcp171776_388440.pdf

ONS (2015a). Chapter 5: Financial wealth, wealth in Great Britain, 2012 to 2014. http://webarchive.nationalarchives.gov.uk/201601051 60709/http://www.ons.gov.uk/ons/dcp171776_428639.pdf

ONS (2015b). Births by parents' characteristics in England and Wales: 2014. http://www.ons.gov.uk/peoplepopulationandcommunity/birthsdeathsandmarriages/livebirths/bulletins/birthsbyparentscharacteristicsinenglandandwales/2014

Santamouris M, Kapsis K, Korres D, Livada I, Pavlou C, Assimakopoulos $\mathrm{M} \mathrm{N}$ (2007). On the relation between the energy and social characteristics of the residential sector. Energy and Building, 39(8): 893-905

Skelton C (2013). Soft City Culture and Technology: The Betaville Project. Springer Publishing Company, Incorporated

Sonderegger R C (1978). Movers and stayers: The resident's contribution to variation across houses in energy consumption for space heating. Energy and Building, 1(3): 313-324

Steg L, Vlek C (2009). Encouraging pro-environmental behaviour: An integrative review and research agenda. Journal of Environmental Psychology, 29(3): 309-317

Van Raaij W F, Verhallen T M M (1983). A behavioral model of residential energy use. Journal of Economic Psychology, 3(1): 39-63

WhatPrice (2017). Advantages and disadvantages of UK house types. http://www.whatprice.co.uk/building/uk-house-types.html

Whiting S (2010). Socio-demographic comparison between those UK families with up to two children and those with three or more. Population Matters. http://populationmatters. org/documents/family_sizes. pdf

Wiesmann D, Lima Azevedo I, Ferrão P, Fernández J E (2011). Residential electricity consumption in Portugal: Findings from topdown and bottom-up models. Energy Policy, 39(5): 2772-2779

Zhou S, Teng F (2013). Estimation of urban residential electricity demand in China using household survey data. Energy Policy, 61: 394-402 